\title{
Pengaruh Penganggaran, Budget Empahasis, Asimetri Informasi Pada Budgetary Slack Dengan Locus Of Control Sebagai Pemoderasi
}

\author{
Kadek Ayu Mika Dwi Riantari ${ }^{1}$ \\ Fakultas Ekonomi dan Bisnis \\ Universitas Udayana, Indonesia. \\ Email: dayueglantier@gmail.com
}

\author{
Maria Mediatrix Ratna Sari ${ }^{2}$ \\ Fakultas Ekonomi dan Bisnis \\ Universitas Udayana, Indonesia.
}

\begin{abstract}
ABSTRAK
Penelitian bertujuan untuk mengetahui pengaruh penganggaran, budget emphasis, asimetri informasi terhadap budgetary slackserta untuk mengetahui locus of control sebagai pemoderasi penganggaran, budget emphasis dan asimetri informasi terhadap budgetary slack BPR di Kabupaten Tabanan. Penelitian dilakukan di BPR yang tersebar di Kabupaten Tabanan. Populasi adalah penyusun anggaran pada 22 BPR di Kabupaten Tabanan. Teknik penentuan sampel adalah purposive sampling dengan kriteria informan yang dipilih telah menduduki jabatan/bagian minimal 2 tahun dan turut berkontribusi dalam penyusunan anggaran. Pengumpulan data dengan menyebarkan kuisioner. Teknik analisis data yang digunakan adalah analisis MRA.Hasil penelitian menunjukan penganggaran, budget empahasis, asimetri informasi berpengaruh positifpada budgetary slack. Locus of control memoderasi pengaruh penganggaran, budget empahasis dan asimetri informasipada budgetary slack.
\end{abstract}

Kata Kunci :

Penganggaran; Budget Empahasis; Asimetri Informasi; Budgetary Slack; Locus of Control.

\section{Influence Budgeting, Budget Empahasis, Information Asymmetry On Budgetary Slack With Locus Of Control As Moderating}

\section{ABSTRACT}

This study aims to determine the effect of budgeting, budget emphasis and information asymmetry on budgetary slack and to find out locus of control as moderating participatory budgeting, budget emphasis and information asymmetry on BPR budgetary slack in Tabanan Regency. This research was carried out by rural banks spread across Tabanan Regency. The population were budget compilers in 22 BPRs. The technique of determining the sample purposive sampling with criteria of selected informants who had occupied the position / part of at least 2 years and contributed to the preparation of the budget. Data collection by distributing questionnaire. Data analysis technique used is MRA. The results indicate that budgetary, empahasis budget, information asyimmetry has a positive effect on budgetary slack. Locus of control moderates the influence of participatory budgeting, budget empahasis and information asymmetry on budgetary slack.

Keywords: $\quad$ Budgeting; Budget Empahasis; Information Asymmetry; Budgetary Slack; Locus Of Control.

\section{$-J U R N A L$
AKUNTANSI \\ E-JA \\ e-JurnalAkuntansi e-ISSN 2302-8556}

Vol. 29 No. 2

Denpasar, November

2019

Hal. 547-560

Artikel masuk:

11 Agustus 2019

Tanggal diterima:

13 Oktober 2019 


\section{PENDAHULUAN}

Persaingan global akan menyebabkan suatu ketidakpastian dalam lingkungan bisnis sehingga menimbulkan kesulitan dalam proses perencanaan dan pengendalian manajemen.Pesatnya perkembangan persaingan bisnis yang ada saat ini memberikan risiko yang tinggi terhadap bagian keuangan perusahaan tersebut, dimana keuangan merupakan alat pengukur sehat atau tidak sehatnya sebuah perusahaan. Fenomena yang terjadi ini juga tidak luput dialami oleh perusahaan perbankan. Bank Perkreditan Rakyat (BPR) adalah lembaga keuangan bank yang menerima simpanan hanya dalam bentuk deposito berjangka, tabungan, atau bentuk lainnya yang dipersamakan dengan itu dan menyalurkan dana kepada masyarakat. BPR memiliki peranan penting dalam melayani kepentingan dan kebutuhan masyarakat dibidang jasa keuangan khususnya untuk Usaha Kecil dan Mikro (Bunga \& Maria, 2017)

Salah satu yang harus diperhatikan terkait dengan fenomena tersebut adalah permasalahan anggaran. Anggaran merupakan salah satu alat manajemen yang berfungsi sebagai alat perencanaan dan pengendalian serta dapat meningkatkan kinerja organisasi dalam mencapai tujuan jangka pendek maupun jangka panjang. Sukarno (2002:169) menyatakan bahwa anggaran adalah rencana yang terorganisasi dan dinyatakan dalam unit moneter untuk operasi dan sumber daya suatu perusahaan selama periode tertentu di masa yang akan datang. Menurut Eka (2016) anggaran merupakan rencana yang dinyatakan dalam unit moneter yang meliputi seluruh kegiatan organisasi dan berlaku untuk jangka waktu tertentu. Sebuah organisasi atau perusahaan memiliki keselaran tujuan maka perlu dibuatkan sistem pengendalian berupa manjaemen pengendalian untuk menyelaraskan tujuan tersebut (Bunga \& Maria, 2017). Salah satu cara manajemen untuk melakukan pengendalian adalah dengan menggunakan sistem pengendalian yang bersifat formal yaitu penganggaran.

(Bunga \& Maria, 2017). menyatakan bahwa proses penyusunan anggaran akan melibatkan banyak pihak, mulai dari manajemen tingkat atas sampai manajemen tingkat bawah akan terlibat. Proses ini juga akan berdampak langsung terhadap prilaku manusia baik prilaku yang bersifat positif atau yang bersifat negatif terutama bagi orang yang terlibat langsung dalam penyusunan anggaran. Perilaku positif dapat berupa peningkatan kinerja manajer karena akan termotivasi oleh anggaran yang digunakan sebagai dasar penilaian kinerja mereka. Perilaku negatif yang mungkin timbul adalah kecenderungan manajer mencipkan senjangan anggaran atau budgetary slack.

Krisnayanti (2017) menjelaskan beberapa alasan seseorang dalam organisasi melakukan senjangan anggaran, yaitu karena seseorang akan percaya bahwa hasil pekerjaan mereka akan terlihat bagus dimata pimpinanya ketika mereka dapat mencapai anggaran yang telah ditetapkan. Penyebab terjadinya senjangan anggaran lainnya adalah perencanaan anggaran selalu dipotong dalam pengalokasian sumberdaya dan senjangan. Faktor yang menimbulkan terjadinya senjangan anggaran atau budgetary slack, diantarnya adalah partisipasi anggaran, locus of control, asimetri informasi dan budget empahasis.

Salah satu kondisi yang paling sering menyebabkan terjadinya budgetary slack adalah partisipasi anggaran. Krisnayanti (2017) menjelasakan bahwa partisipasi anggaran dapat menimbulkan tiga masalah yaitu dapat menetapkan 
anggaran terlalu tinggi atau terlalu rendah, membuat kelonggaran dalam anggaran (budgetary slack), dan partispasi semu. Partisipasi penganggaran memberikan kesempatan semua tingkat manajer baik tingkat atas, menengah, dan bawah untuk melakukan senjangan demi kepentingan pribadinya. Sawitri (2014) menemukan bahwa ketika partisipasi anggaran yang dilakukan oleh bawahan semakin besar maka akan menimbulkan budgetary slack yang semakin besar pula.

Kebijakan anggaran mengekspresikan komitmen atasan kepada bawahannya secara konkrit (Kren, 2003). Hasil penelitian Soobaroyen (2005), menunjukkan bahwa partisipasi anggaran partisipatif berpengaruh signifikan terhadap senjangan anggaran. Penelitian Arthaswadaya (2015:2) menunjukkan bahwa partisipatif anggaran merupakan proses yang individu-individu di dalamnya terlibat dan mempunyai pengaruh atas penyusunan target anggaran yang kinerjanya di evaluasi dan mungkin dihargai atas dasar pencapaian target anggaran dan mendapat sanksi apabila perencanaan anggaran tidak tercapai.

Threzasyari (2017) berpendapat bahwa senjangan anggaran adalah perbedaan anggaran yang dilaporkan dengan anggaran yang sesuai dengan estimasi terbaik bagi organisasi. Hasil penelitian Triana (2012), menyatakan bahwa budget emphasis berpengaruh memiliki pengaruh terhadapanggaran.

Asimetri informasi merupakan faktor yang juga mempengaruhi terjadinya senjangan anggaran adalah budgetary slack. Anggaran memiliki fungsi sebagai perencanaan dan pengendalian perusahaan. Pimpinan akan memberikan wewenang terhadap manager pusat untuk menyusun anggarannya. Kewenangan tersebut memberi celah bagi para partisipan dalam menyalahgunakan wewenang serta informasi yang ada dengan memberikan informasi yang cenderung bias kepada pimpinannya (asimetri informasi) dengan tujuan mempermudah pencapaian anggaran. Menurut Suartana (2010: 143) pengaruh asimetri informasi terhadap budgetary slack bahwa senjangan anggaran atau budgetary slack menjadi lebih besar saat adanya kondisi asimetri informasi karena asimetri informasi mendorong bawahan/ pelaksana anggaran membuat senjangan anggaran.

Penelitian tentang budgetary slack sudah banyak dilakukan tetapi masih banyak ditemukan perbedaan hasil. Lukka (1988) dan Young (1985) memeberikan hasil partisipasi anggaran memberikan hasil yang positif serta meningkatnya adanya budgetary slack. Penelitian ini sejalan dengan penelitian yang dilakukan oleh Maya et al (2010), Threzasyari (2017) yang menyatakan bahwa partisipasi anggaran mempengaruhi terjadinya budgetary slack. Namun, penelitian lain menjelaskan bahwa partisipasi anggaran tidak berpengaruh terhadap budgetary slack, beberapa penelitian yang memberikan hasil ini adalah Schift dan Lewin (1970), Onsi (1973), Camman (1976), Merchant (1985) menurut penelitian ini tidak adanya pengaruh antara partisipasi anggaran dengan budgetary slack karena agen mencoba untuk memberikan informasi pada prinsipan mengenai prospek dimasa depan, jadi penyusunan anggaran jadi lebih akurat. Penelitian mengenai asimetri informasi dilakukan oleh Faruq (2013) menghasilkan simpulan asimetri informasi memiliki pengaruh positif terhadap budgetary slack ini sejalan dengan penelitian yang dilakukan(Bunga \& Maria, 
2017). Sedangkan Wenny (2012) yang menyebutkan bahwa tidak terdapat pengaruh yang signifikan antara asimetri informasi dengan budgetary slack.

Ketidakkonsistenan hasil penelitian pun terjadi pada penelitian pengaruh penekanan anggaran terhadap budgetary slack. Dunk (1993) dalam penelitiannya mengajukan hipotesis bahwa tidak ada interaksi antara partisipasi anggaran, asimetri informasi dan penekanan anggaran yang memengaruhi senjangan anggaran, namun hasil penelitiannya menunjukkan adanya hubungan antara partisipasi dengan senjangan justru tergantung pada informasi asimetri dan penekanan anggaran. Berbeda dengan penelitian Ramdeen et al (2006)yang mengadakan penelitian untuk menguji pengaruh partisipasi anggaran, penekanan anggaran dan asimetri informasi terhadap senjangan anggaran.

Hipotesis yang diajukan dalam penelitian ini mengatakan bahwa terdapat interaksi positif antara partisipasi anggaran, penekanan anggaran dan asimetri informasi terhadap senjangan anggaran, akan tetapi hasil dalam penelitiannya pun menunjukan interaksi yang sebaliknya yaitu hubungan antara partisipasi anggaran dengan senjangan anggaran yang bergantung pada penekanan anggaran dengan asimetri informasi memiliki hubungan negatif. Perbedaan hasil penelitian pun terjadi pada penelitian Sujana (2010) yang menyatakan bahwa budget emphasis tidak memiliki pengaruh secara signifikan terhadap anggaran, sedangkan penelitian Afiani (2010) dan Purgianto (2009) menunjukkan hasil yang siginifikan antara pengaruh budget emphasis terhadap anggaran.

Hasil penelitian Govindarajan (1986) juga menyatakan bahwa perbedaan hasil penelitian terhadap pengaruh budgetary slack dapat dilakukan dengan pendekatan kontijensi. Hal ini dilakukan dengan cara memasukkan variabel lain yang mungkin memparuhi hubungan pertispasi anggran dengan budgetary slack adalah asimetri informasi, self esteem dan locus of controldan kapasitas individu sebagai variabel pemodersi. Pada penelitian ini yang digunakan sebagai variabel pemoderasi adalah variabel locus of control.

Locus of controladalahkeyakinan yang dimiliki oleh individu dalam mengendalikan setiap kejadian yang dialami (Hapsari, 2010). Locus of controldapat dibagi menjadi dua yaitu locus of control internal dan locus of control external. Locus of control internal menggambarkan sejauh mana orang-orang mengharapkan pengakuan terhadap hasil kerja mereka sendiri, sedangkan locus of control external menggambarkan sejauh mana orang-orang mengharapkan penguatan yang bukan muncul dari diri orang tersebut, tetapi dipengaruhi oleh faktor lingkungannya. Menurut Falikhatun (2003), menyatakan bahwa locus of control internal lebih berorientasi kepada tugas-tugas yang dihadapi seorang indvidu, dimana locus of control memegang peranan yang penting untuk mengontrol lingkungan sehingga tercipta lingkungan kerja yang lebih baik dan pemanfaatan informasiyang lebih baik dalam situasi pengambilan keputusan yang komplek.

Ketidakkonsistenan hasil penelitian tersebut yang melatarbelakangi penelitian ini untuk terus dilanjutkan. Adi dan Mardiasmo (2002) melakukan penelitian dengan menggunakan variabel locus of control sebagai variabel pemoderasi, dan hasil penelitianya menunjukan bahwa locus of control memiliki pengaruh yang positif teradap budgetary slack, karena banyak ketidakkonsistenan 
hasil penelitian maka dalam penelitian ini peneliti menggunakan variabel locus of control sebagai variabel pemoderasi.

Widi (2002) menjelaskan bahwa informasi yang lebih baik tentang tingkat kecukupan anggaran yang dikehendaki untuk melaksanakan tugas-tugasnya dimiliki oleh bawahan dan mereka akan berusaha memasukan informasi ini ke dalam anggaran. Afiani (2010) menyebutkan bahwa manajer tingkat bawah mengaharapkan mendapatkan keuntungan melalui senjangan anggaran mereka, maka mereka harus meningkatkan partisipasinya dalam proses penyusunan anggaran. Hasil dari hipotesis adalah adanya pengaruh partisipasi anggaran terhadap senjangan anggaran (budgetary slack).

$\mathrm{H}_{1}$ : Penganggaran partisipatif berpengaruh positif terhadap budgetary slack.

Budget Empahasis atau penekanan anggaran merupakan pemberiaan reward atau penilaian kinerja bagi bagi bawahan berdasarkan pada pencapaian target anggaran atau apabila pempinan berpendapat bahwa kinerja dan penghargaannyadinilai berdasarkan pada target anggaran yang dicapai budget empahasis ini akan menjadi tekanan bagi bawahan untuk memberikan yang terbaik dengan mencari peluang-peluang tertentu yang menguntungkan. Peluang inilah yang akan menyebabkan suatu senjangan (Sujana, 2010). Hasil penelitian Veronica (2009) dan Triana (2012) juga mengemukakan bahwa penekanan anggaran berpengaruh positif terhadap senjangan anggaran.

$\mathrm{H}_{2}$ : Budget empahasis berpengaruh positifpada budgetary slack.

Asimetri informasi merupakan perbedaan informasi yang dimiliki antara prisipel dengan agen, dalam penelitian ini adalah perbedaan informasi antara pemilik dan pengelola BPR. Selanjutnya pengaruh timbulnya budgetary slack menurut Suartana (2010) bahwa senjangan anggaran akan menjadi lebih besar dalam kondisi informasi asimetris karena informasi asimetri mendorong bawahan/ pelaksana anggaran membuat senjangan anggaran. Berdasarkan penelitian Eka (2016), ditemukan bahwa ada asimetri informasi memiliki arah pengaruh yang positif terhadap senjangan anggaran. Lebih lanjut menurut penelitian Pallo (2014) menyatakan bahwa asimetris informasi berpengaruh signifikan pada hubungan antara penganggran partisipatif terhadap senjagan anggran.

$\mathrm{H}_{3}$ : Asimetri informasiberpengaruh positif pada budgetary slack.

Hasil penelitian Sandrya (2013) yang menyatakan bahwa kapasitas individu tidak mampu memperlemah pengaruh penganggaran partisipatif pada budgetary slack, karena kapasitas individu merupakan perpaduan dari kemampuan dan keterampilan individu dan tidak dapat digunakan untuk menilai tingkat motivasinya dalam melakukan budgetary slack. Maskun (2008) berpendapat bahwa, semakin tinggi tingkat pendidikan, maka semakin positif pandangannya pada budgetary slack. Berdasarkan penelitian Threzasyari (2017) mengungkapkan bahwa locus of control memoderasi pengaruh antara partisipasi anggaran dengan budgetary slack.

$\mathrm{H}_{4}$ : Locus of control memoderasi pengaruh penganggaran partisipatif pada budgetary slack.

Berdasarkan penelitian Triana (2012) ditemukan adanya pengaruh antara budget empahasis terhadap budgetary slack. Hasil penelitian Purnomo (2006), menyatakan bahwa budget empahasis berpengaruh signifikan terhadap terjadinya 
kesenjangan anggaran. Hasil penelitian Dunk (1993) juga menujukkan bahwa budget empahasis akan mendorongmanajer untuk menurunkan senjangan anggran.

$\mathrm{H}_{5}$ : Locus of control memoderasi pengaruh budget empahasis pada budgetary slack.

Menurut Suartana (2010) bahwa senjangan anggaran akan menjadi lebih besar dalam kondisi informasi asimetris karena informasi asimetri mendorong bawahan/ pelaksana anggaran membuat senjangan anggaran. Berdasarkan penelitian Eka (2016), ditemukan bahwa ada asimetri informasi memiliki arah pengaruh yang positif terhadap senjangan anggaran serta dimoderasi oleh variabel locus of control.

$\mathrm{H}_{6}$ : Locus of control memoderasi pengaruh asimetri informasipada budgetary slack.

\section{METODE PENELITIAN}

Pendekatan yang digunakan dalam penelitian ini adalah pendekatan kuantitatif. Lokasi penelitian merupakan suatu tempat atau wilayah penelitian tersebut akan dilakukan. Lokasi diadakannya penelitian yaitu di Bank Perkreditan Rakyat (BPR) yang berada di Kabupaten Tabanan.

Variabel bebas dalam penelitan ini adalah partisipasi anggaran, budget emphasis, dan asimetri informasi. Partisipasi anggaran merupakan keterlibatan manajer dalam penyusunan anggaran. Indikator yang digunakan untuk mengukur partisipasi anggaran adalah keikutsertaan dalam penyusunan anggaran, besarnya pengaruh terhadap penetapan anggaran, dan kebutuhan memberikan pendapat Yocky (2013).

Budget emphasis adalah desakan dari atasan pada bawahan untuk melaksanakan anggaran yang telah dibuat dengan baik, yang berupa sangsi jika kurang dari target anggaran dan kompensasi jika mampu melebihi target anggaran. Indikator yang digunakan untuk mengukur budget emphasis adalah fokus pada pekerjaan,perhatian terhadap kualitas, kemampuan pencapaian target, harmonisasi dalam lingkungan kerja, efisiensi dan sikap terhadap pekerjaan Yocky (2013).

Asimetri informasi adalah ketidakseimbangan informasi yang dimiliki bawahan dengan informasi yang dimiliki atasan mengenai suatu unit tanggung jawab pada perusahaan. Indikator yang digunakan untuk mengukur asimetri informasia adalah informasi yang dimiliki bawahan dibandingkan dengan atasan, hubungan input-output yang ada dalam operasi internal, kinerja potensial, teknis pekerjaan, mampu menilai dampak potensial dan pencapaian bidang kegiatan (Armaeni, 2012).

Variabel terikat dalam penelitian ini adalah budgetary slack. Variabel budgetary slack adalahperbedaan/selisih antara sumber daya yang sebenarnya dibutuhkan untuk melaksanakan sebuah pekerjaan dengan sumber daya yang diajukan dalam anggaran. Indikator budgetary slack menurut Onsi (1973) adalah perbedaan jumlah anggaran yang dinyatakan dengan estimasi terbaik, kelonggaran dalam anggaran, standar anggaran, keinginan untuk mencapai target.

Variabel pemoderasi dalam penelitian ini adalah locus of control. Variabel locus of control adalah tingkat kepercayaan diri yang dimiliki oleh manajer dalam 
menilai kinerjanya. Indikator locus of controlmenurut Robbins (1998) adalah kepercayaan akan adanya takdir, kepercayaan diri, dan usaha/kerja keras.

Sumber data yang digunakan merupakan data primer. Data primer adalah data penelitian yang diperoleh langsung dari sumber asli, sehingga data primer dalam penelitian ini adalah berupa jawaban responden terhadap item-item pertanyaan yang terdapat dalam lima instrumen penelitian yaitu partisipasi anggaran, budget emphasis, asimetri informasi, budgetary slack, dan locus of control.

Populasi mengacu pada keseluruhan kelompok orang, kejadian atau hal yang ingin peneliti investigasi.Populasi dalam penelitian ini adalah penyusun anggaran pada 22 BPR di Kabupaten Tabanan. Sampel adalah bagian dari jumlah dan karakteristik yang dimiliki oleh populasi (Sugiyono, 2013:116). Sampel yang digunakan adalah kepala bagian beserta staf di masing-masing bagian pada 22 BPR di Kabupaten Tabanan. Teknik analisis yang digunakan dalam penelitian ini adalah analisis regresi berganda dan Moderated Regression Analysis (MRA). Teknik analisis regresi linear berganda bertujuan untuk mengetahui pengaruh variable bebas majemuk terhadap variabel terikatnya. Menurut Suyana (2009) model regresi linear berganda dapat ditunjukkan oleh persamaan berikut:

$$
Y=a+b_{1} X_{1}+b_{2} X_{2}+b_{3} X_{3}+\mu
$$

Keterangan:

$$
\begin{array}{ll}
\mathrm{Y} & =\text { Budgetary Slack } \\
a & =\text { Konstanta } \\
\mathrm{X}_{1} & =\text { Partisipasi Anggaran } \\
\mathrm{X}_{2} & =\text { Budget Emphasis } \\
\mathrm{X}_{3} & =\text { Asimetri Informasi } \\
\mathrm{b}_{1}-\mathrm{b}_{3} & =\text { Koefisien regresi } \\
\mu & =\text { error }
\end{array}
$$

Moderated Regression Analysis (MRA) merupakan aplikasi khusus untuk regresi linier berganda.Moderated Regression Analysis (MRA)dalam persamaan regresinya mengandung interaksi, yaitu perkalian dua atau lebih variabel independen. Persamaan moderated regression analysis sebagai berikut:

$$
\mathrm{Y}=a+\mathrm{b}_{1} \mathrm{X}_{1}+\mathrm{b}_{2} \mathrm{X} 2+\mathrm{b}_{3} \mathrm{X}_{3}+\mathrm{b}_{4}\left(\mathrm{X}_{1} \cdot \mathrm{Z}\right)+\mathrm{b}_{5}\left(\mathrm{X}_{2} \cdot \mathrm{Z}\right)+\mathrm{b}_{6}\left(\mathrm{X}_{3} \cdot \mathrm{Z}\right)+\mu
$$

Keterangan :

$$
\begin{array}{ll}
\mathrm{Y} & =\text { Budgetary Slack } \\
a & =\text { Konstanta } \\
\mathrm{X}_{1} & =\text { Partisipasi Anggaran } \\
\mathrm{X}_{2} & =\text { Budget Emphasis } \\
\mathrm{X}_{3} & =\text { Asimetri Informasi } \\
\mathrm{Z} & =\text { Locus of control } \\
\mathrm{b}_{1}-\mathrm{b}_{6} & =\text { Koefisien regresi } \\
\mathrm{X}_{1 .} \mathrm{Z} & =\text { Interaksi partisipasi anggaran dengan budgetary slack } \\
\mathrm{X}_{2} \mathrm{Z} & =\text { Interaksi budget emphasis dengan budgetary slack } \\
\mathrm{X}_{3} \mathrm{Z} & =\text { Interaksi asimetri informasi dengan budgetary slack } \\
\mu & =\text { error }
\end{array}
$$




\section{HASIL DAN PEMBAHASAN}

Statistik deskriptif digunakan untuk memberikan gambaran dari suatu data yang dilihat dari jumlah sampel, nilai minimum, nilai maksimum, nilai rata-rata (mean), dan standar deviasi dari masing-masing variabel di dalam penelitian. Hasil analisis data untuk statistik deskriptif yang dapat dilihat pada Tabel 1.

Tabel 1. Hasil Statistik Deskriptif

\begin{tabular}{lccccc}
\hline \multicolumn{1}{c}{ Variabel } & N & Min. & Max. & Mean & $\begin{array}{c}\text { Std. } \\
\text { Deviasi }\end{array}$ \\
\hline partisipasi anggaran $\left(\mathrm{X}_{1}\right)$ & 80 & 14 & 27 & 23,56 & 2,968 \\
budget empahasis $\left(\mathrm{X}_{2}\right)$ & 80 & 24 & 28 & 25,56 & 1,491 \\
asimetri informasi $\left(\mathrm{X}_{3}\right)$ & 80 & 22 & 29 & 25,63 & 1,679 \\
budgetary slack $(\mathrm{Y})$ & 80 & 26 & 33 & 29.72 & 2,233 \\
locus of control $(\mathrm{Z})$ & 80 & 26 & 33 & 9.50 & 2,081 \\
\hline
\end{tabular}

Sumber: Data Penelitian, 2018

Berdasarkan Tabel. 1 menunjukkan bahwa jumlah pegamatan $(\mathrm{N})$ pada penelitian ini adalah sebanyak 80 . Variabel partisipasi anggaran $\left(\mathrm{X}_{1}\right)$ memiliki nilai minimum sebesar 14 dan nilai maksimum sebesar 27 dengan nilai rata-rata sebesar 23,56 jika dibagi dengan 6 item pertanyaan akan menghasilkan nilai sebesar 3,93 yang artinya rata-rata responden memberikan skor 4 untuk item pertanyaan partisipasi anggaran. Standar deviasi pada variabel partisipasi anggaran adalah sebesar 2,96. Hal ini menunjukkan bahwa standar penyimpangan data terhadap nilai rata-ratanya adalah 2,96.

Variabel budget emphasis $\left(\mathrm{X}_{2}\right)$ memiliki nilai minimum sebesar 24 dan nilai maksimum sebesar 28 dengan nilai rata-rata sebesar 25,56 jika dibagi dengan 6 item pertanyaan akan menghasilkan nilai sebesar 4,26 yang artinya rata-rata responden memberikan skor 4 untuk item pertanyaan budget emphasis. Standar deviasi pada variabel budget emphasis adalah sebesar 1,49. Hal ini menunjukkan bahwa standar penyimpangan data terhadap nilai rata-ratanya adalah 1,49.

Variabel asimetri informasi $\left(X_{3}\right)$ memiliki nilai minimum sebesar 22 dan nilai maksimum sebesar 29 dengan nilai rata-rata sebesar 25,63, jika dibagi dengan 6 item pertanyaan akan menghasilkan nilai sebesar 4,27 yang artinya rata-rata responden memberikan skor 4 untuk item pertanyaan asimetri informasi. Standar deviasi pada variabel asimetri informasi adalah sebesar 1,67. Hal ini menunjukkan bahwa standar penyimpangan data terhadap nilai rataratanya adalah 1,67.

Variabel budgetary slack (Y) memiliki nilai minimum sebesar 26, dan nilai maksimum sebesar 33 dengan nilai rata-rata sebesar 29,72, jika dibagi dengan 7 item pertanyaan akan menghasilkan nilai sebesar 4,24 yang artinya rata-rata responden memberikan skor 4 untuk item pertanyaan budgetary slack. Standar deviasi pada variabel budgetary slack adalah sebesar 2,23. Hal ini menunjukkan bahwa standar penyimpangan data terhadap nilai rata-ratanya adalah 2,23.

Variabel locus of control (Z) memiliki nilai minimum sebesar 26 dan nilai maksimum sebesar 33 dengan nilai rata-rata sebesar 29,50, jika dibagi dengan 7 item pertanyaan akan menghasilkan nilai sebesar 4,21 yang artinya rata-rata responden memberikan skor 4 untuk item pertanyaan locus of control. Standar 
deviasi pada variabel locus of control adalah sebesar 2,08. Hal ini menunjukkan bahwa standar penyimpangan data terhadap nilai rata-ratanya adalah 2,08.

Pengujian berikutnya adalah uji instrumen yang meliputi uji validitas dan reliabilitas. Berdasarkan hasil uji validitas dengan SPSS menujukkan hasil bahwa instrumen penelitian yang terdiri dari item-item pertanyaan partisipasi anggaran $\left(\mathrm{X}_{1}\right)$, budget emphasis $\left(\mathrm{X}_{2}\right)$, asimetri informasi $\left(\mathrm{X}_{3}\right)$, budgetary slack $(\mathrm{Y})$, dan locus of control(Z) adalah valid. Hal ini dikarenakan korelasi antara skor masing-masing pertanyaan dengan skor total besarnya diatas 0,30.Uji reliabilitas juga menunjukkan bahwa variabel partisipasi anggaran $\left(\mathrm{X}_{1}\right)$, budget emphasis $\left(\mathrm{X}_{2}\right)$, asimetri informasi $\left(\mathrm{X}_{3}\right)$, budgetary slack $(\mathrm{Y})$ dan local of control $(\mathrm{Z})$ memiliki nilai koefisien alpha cronbach's diatas 0,60 sehingga terbukti reliabel.

Sebelum dianalisis dengan teknik regresi, maka model persamaan regresi harus melalui uji asumsi klasik. Model regresi yang baik adalah model regresi yang di dalamnya tidak terdapat masalah data yang distribusinya normal, masalah multikolinearitas, dan masalah heteroskedastisitas. Berdasarkan Tabel. 2 dapat dilihat bahwa nilai signifikansi dari ketiga model persamaan tersebut adalah 0,200. Hal ini menunjukkan bahwa ketiga model persamaan memenuhi uji normalitas karena nilai Asymp.S ig lebih besar dari 0,05.

Tabel 2. Hasil Uji Normalitas

\begin{tabular}{cc}
\hline Persamaan & Asymp. Sig \\
\hline $\mathrm{Y}=\mathrm{a}_{1}+\mathrm{b}_{1} \mathrm{X}_{1}+\mathrm{b}_{4} Z+\mathrm{b}_{7} \mathrm{X}_{1} Z+\mathrm{e}_{1}$ & 0,200 \\
$\mathrm{Y}=\mathrm{a}_{2}+\mathrm{b}_{2} \mathrm{X}_{2}+\mathrm{b}_{5} Z+\mathrm{b}_{8} \mathrm{X}_{2} Z+\mathrm{e}_{2}$ & 0,200 \\
$\mathrm{Y}=\mathrm{a}_{3}+\mathrm{b}_{3} \mathrm{X}_{3}+\mathrm{b}_{6} Z+\mathrm{b}_{9} \mathrm{X}_{3} Z+\mathrm{e}_{3}$ & 0,200 \\
\hline
\end{tabular}

Sumber: Data Penelitian, 2018

Uji heteroskedastisitas bertujuan menguji apakah dalam model regresi terjadi ketidaksamaan varians dari residual satu pengamatan ke pengamatan lain. Uji heteroskedastisitas dalam penelitian ini dilakukan dengan uji Glejser. Tabel.2 menunjukkan bahwa nilai signifikansi masing-masing variabel pada ketiga model regresi besarnya melebihi 0,05 yang artinya ketiga model regresi dalam penelitian ini bebas dari gejala heteroskedastisitas.

Tabel 3. Hasil Uji Heteroskedastisitas

\begin{tabular}{|c|c|c|}
\hline Persamaan & Variabel & Sig \\
\hline \multirow[t]{3}{*}{$Y=a_{1}+b_{1} X_{1}+b_{4} Z+b_{7} X_{1} Z+e_{1}$} & $\mathrm{X} 1$ & 0,353 \\
\hline & Z & 0,709 \\
\hline & X1_Z & 0,451 \\
\hline \multirow[t]{3}{*}{$Y=a_{2}+b_{2} X_{2}+b_{5} Z+b_{8} X_{2} Z+e_{2}$} & $\mathrm{X} 2$ & 0,798 \\
\hline & $\mathrm{Z}$ & 0,399 \\
\hline & $\mathrm{X} 2 \_\mathrm{Z}$ & 0,257 \\
\hline \multirow[t]{3}{*}{$Y=a_{3}+b_{3} X_{1}+b_{6} Z+b_{9} X_{3} Z+e_{3}$} & $\mathrm{X} 3$ & 0,362 \\
\hline & Z & 0,066 \\
\hline & X3_Z & 0,853 \\
\hline
\end{tabular}

Sumber : Data Penelitian, 2018

Uji multikolinieritas bertujuan untuk menguji apakah dalam model regresi ditemukan adanya korelasi antar variabel bebas.Tabel.3 menunjukkan nilai tolerance pada masing-masing variabel diatas 0,1 dan nilai VIF dibawah 10, yang berarti tidak terjadi multikolinieritas. 
Tabel 4. Hasil Uji Multikolinieritas

\begin{tabular}{cccc}
\hline \multirow{2}{*}{ Persamaan } & \multirow{2}{*}{ Variabel } & \multicolumn{2}{c}{ Collinearity Statistic } \\
\cline { 3 - 4 } $\mathrm{Y}=\mathrm{a}_{1}+\mathrm{b}_{1} \mathrm{X}_{1}+\mathrm{b}_{4} \mathrm{Z}+\mathrm{b}_{7} \mathrm{X}_{1} \mathrm{Z}+\mathrm{e}_{1}$ & $\mathrm{X} 1$ & 0,120 & Tolerance \\
& $\mathrm{Z}$ & 0,275 & 3,314 \\
& $\mathrm{X} 1 \_\mathrm{Z}$ & 0,185 & 7,771 \\
$\mathrm{Y}=\mathrm{a}_{2}+\mathrm{b}_{2} \mathrm{X}_{2}+\mathrm{b}_{5} \mathrm{Z}+\mathrm{b}_{8} \mathrm{X}_{2} \mathrm{Z}+\mathrm{e}_{2}$ & $\mathrm{X} 2$ & 0,358 & 2,793 \\
& $\mathrm{Z}$ & 0,261 & 3,834 \\
$\mathrm{Y}=\mathrm{a}_{3}+\mathrm{b}_{3} \mathrm{X}_{1}+\mathrm{b}_{6} \mathrm{Z}+\mathrm{b}_{9} \mathrm{X}_{3} \mathrm{Z}+\mathrm{e}_{3}$ & $\mathrm{X} \_\mathrm{Z}$ & 0,159 & 6,276 \\
& $\mathrm{X} 3$ & 0,245 & 4,088 \\
& $\mathrm{Z}$ & 0,225 & 4,448 \\
& $\mathrm{X} 3 \_\mathrm{Z}$ & 0,102 & 9,798 \\
\hline
\end{tabular}

Sumber : Data Penelitian, 2018

Pengujian selanjutnya adalah uji hipotesis penelitian. Berdasarkan hasil analisis menujukkan hasil signifikan uji $t$ pada variabel interaksi partisipasi anggaran (X1) dengan budgetary slack (Z) adalah sebesar 0,048< $\mathrm{\alpha}=0,05 \mathrm{maka}_{0}$ ditolak dan $\mathrm{H}_{1}$ dapat diterima, maka dapat disimpulkan bahwa partisipasi anggaransecara parsial berpengaruh positif terhadap budgetary slack $(\mathrm{Y})$.

Hasil penelitian ini sesuai dengan penelitian Nouri (1994) dalam Arfan \& La (2007:10) menunjukkan bahwa partisipasi penyusunan anggaran mempunyai hubungan positif dengan kecukupan anggaran dan secara tidak langsung mempengaruhi hubungan partisipasi penyusunan anggaran. Selanjutnya Afiani (2010) menyebutkan bahwa manajer tingkat bawah mengaharapkan mendapatkan keuntungan melalui senjangan anggaran mereka, maka mereka harus meningkatkan partisipasinya dalam proses penyusunan anggaran. Partisipasi rendah, maka kesempatan bagi manajer bawah untuk menciptakan senjangan dalam anggarannya sangat kecil dengan mengabaikan penyajian penekanan anggaran.

Hasil signifikan uji t pada variabel interaksi budget emphasis (X2) dengan budgetary slack $(\mathrm{Z})$ adalah sebesar $0,016<\mathrm{\alpha}=0,05$ maka $\mathrm{H}_{0}$ ditolak dan $\mathrm{H}_{2}$ dapat diterima, maka dapat disimpulkan bahwa budget emphasissecara parsial berpengaruh positif terhadap budgetary slack (Y). Hasil penelitian ini sesuai dengan teori dua faktor Herzberg menjelaskan bahwa faktor-fasktor seperti kebijkan, administrasi perusahaan dan gaji yang memadai dalam suatu pekerjaan akan menentramkan karyawan (Robbins, 2001:170). Adanya penekanan anggaran seperti itu akan mendorong bawahan untuk menciptakan senjangan dengan tujuan meningkatkan prospek kompensasi dan menghindari sanksi Ardin (2017). Hasil penelitian ini sesuai dengan penelitian Veronica (2009) dan Triana (2012) juga mengemukakan bahwa penekanan anggaran berpengaruh positif terhadap senjangan anggaran.

Berdasarkan hasil perhitungan dengan menggunakan uji Moderated Regression Analysis (MRA) menujukkan bahwa uji t pada variabel interaksi asimetris informasi (X3) dengan budgetary slack (Z) adalah sebesar $0,010<\mathrm{a}=$ 0,05maka $\mathrm{H}_{0}$ ditolak dan $\mathrm{H}_{3}$ dapat diterima, maka dapat disimpulkan bahwa asimetris informasisecara parsial berpengaruh positif terhadap budgetary slack 
(Y). Hasil penelitian ini sesuai dengan penelitian Eka (2016), ditemukan bahwa ada asimetri informasi memiliki arah pengaruh yang positif terhadap senjangan anggaran. Lebih lanjut menurut penelitian Pallo (2014) menyatakan bahwa asimetris informasi berpengaruh signifikan pada hubungan antara penganggran partisipatif terhadap senjagan anggran. Semakin tinggi asimetri informasi maka akan semakin tinggi terjadinya senjangan anggaran. Asimetri informasi merupakan perbedaan informasi yang dimiliki antara prisipel dengan agen, dalam penelitian ini adalah perbedaan informasi antara pemilik dan pengelola BPR.

Hasil analisis MRA menujukkan hasil signifikan uji $\mathrm{t}$ pada variabel interaksi budget emphasis (X2) dengan locus of control (Z) terhadapbudgetary slack $(\mathrm{Y})$ adalah sebesar $0,030<\mathrm{\alpha}=0,05$ maka $\mathrm{H}_{0}$ ditolak dan $\mathrm{H}_{4}$ dapat diterima, maka dapat disimpulkan bahwa interaksi budget emphasis dengan locus of control secara individual berpengaruh terhadap budgetary slack (Y).

Berdasarkan teori motivasi menjelaskan bahwa motivasi akan mempengaruhi perilaku seseorang dalam bekerja. Motivasi akan mempengaruhi orang untuk bekerja dan melalui locus of control akan mempengaruhi sejauh mana seseorang bisa menyelesaikan pekerjaan. Sinaga (2013) menyatakan locus of control adalah sampai sejauh mana orang yakin bahwa mereka menguasai nasib mereka sendiri.

Hasil penelitian ini sesuai dengan penelitian Threzasyari (2017) mengungkapkan bahwa locus of control memoderasi pengaruh antara Partisipasi anggaran dengan budgetary slack. Lebih lanjut Dunk (1993) dan Nouri (1994) mengemukakan bahwa bila manager berpandangan bahwa faktor penentu berada dalam kendali individu (internal locus of control), maka manajer akan berusaha secara optimal untuk mempengaruhi organisasi agar dapat mencapai target yang ditentukan. Sebaliknya, bila manager berpandangan bahwa faktor pengendali berada diluar kendali organisasi (external locus of control), maka manajer akan merasa tidak berdaya untuk menggerakkan organisasi mencapai sasaran yang ingin dicapai dalam anggaran. Dengan demikian, manajer akan termotivasi untuk menciptakan budgetary slack serta tindakan penyimpangan lainnya untuk memungkinkan tercapainya sasaran organisasi.

Hasil signifikan uji t pada variabel interaksi budget empahasis (X2) dengan locus of control $(\mathrm{Z})$ terhadap budgetary slack $(\mathrm{Y})$ adalah sebesar $0,030<\alpha=0,05$ maka $\mathrm{H}_{0}$ ditolak dan $\mathrm{H}_{5}$ dapat diterima, maka dapat disimpulkan bahwa interaksi budget empahasis dengan locus of control secara individual berpengaruh terhadap budgetary slack (Y).Hal ini menujunjukanlocus of control memoderasi pengaruh budget emphasis terhadap budgetary slack.

Penilaian kinerja seseorang ditentukan berdasarkan tercapai atau tidaknya target anggaran dimana bawahan dirangsang dengan adanya suatu reward jika perencanaan anggaran tercapai, dan sanksi apabila perencanaan anggaran tidak tercapai. Hasil penelitian ini didukung penelitian Purnomo (2006), menyatakan bahwa budget empahasis berpengaruh signifikan terhadap terjadinya kesenjangan anggaran. Hasil penelitian Dunk (1993) juga menujukkan bahwa budget empahasis akan mendorongmanajer untuk menurunkan senjangan anggran. Anggaran merupakan kunci perencananan, koordinasi dan 
pengawasan manajemen harus dirancang sedemikian rupa agar tidak terlalu sulit di capai.

Hasil signifikan uji t pada variabel interaksi asimetris informasi (X3) dengan locus of control $(\mathrm{Z})$ terhadapbudgetary slack $(\mathrm{Y})$ adalah sebesar $0,000<\mathrm{\alpha}=$ 0,05maka $\mathrm{H}_{0}$ ditolak dan $\mathrm{H}_{1}$ dapat diterima, maka dapat disimpulkan bahwa interaksi asimetris informasi dengan locus of control secara individual berpengaruh terhadap budgetary slack $(\mathrm{Y})$.Hal ini menujunjukanlocus of control memoderasi pengaruh asimetris informasi terhadap budgetary slack.Semakin tinggi asimetri informasi maka akan semakin tinggi terjadinya senjangan anggaran. Penelitian ini didukung oleh penelitian (Eka, 2016), ditemukan bahwa ada asimetri informasi memiliki arah pengaruh yang positif terhadap senjangan anggaran serta dimoderasi oleh variabel locus of control.

\section{SIMPULAN}

Berdasarkan hasil analisis menunjukkan bahwa Partisipasi anggaranberpengaruh positifpada budgetary slack. Budget empahasis berpengaruh positifpada budgetary slack. Asimetri informasi berpengaruh positif pada budgetary slack. Locus of control memoderasi pengaruh partisipasi penganggaran pada budgetary slack. Locus of control memoderasi pengaruh budget empahasis pada budgetary slack. Locus of control memoderasi pengaruh asimetri informasipada budgetary slack.

Saran yang dapat diberikan dari hasil penelitian adalah kepada pihak Bank BPR di Kabupaten Tabanan hendaknya meningkatkan kerjasama dengan bawahan yang lebih erat lagi dalam proses penyusunan anggaran melalui partisipasi penganggaran agar dapat menurunkan terciptanya senjangan anggaran. Selain itu, manajemen BPR hendaknya bisa merancang mekanisme pelaksanaan kelanjutan perusahaannya dengan baik. Selain itu, Pihak BPR harus lebih selektif dalam memilih pejabat yang nantinya akan berpartisipasi dalam penyusunan anggaran yaitu yang memiliki informasi yang pasti dan locus of control yang tinggi, karena dengan memiliki informasi yang pasti dan locus of control yang tinggi seseorang akan merasa mampu menyelesaikan pekerjaan dengan hasil yang optimal, sehingga menurunkan terjadinya budgetary slack.

\section{REFERENSI}

Arfan, I., \& La, A. (2007). Pengaruh Partisipasi Anggaran terhadap BudgetarySlack dengan Menggunakan Lima Variabel Pemoderasi. Simposium Nasional Akuntansi 10 Makassar.

Blau, B.A and Boal, B.K. (1987). Conceptualizing How Job Involvement and Organizational Commitment Affect Turnover and Absenteism. Academy of Management Review, 12, 288-302.

Brownell, Peter. (1982). The Role of Accounting Data Performance Evaluation Budgetary Partisipative, and Organizational Effectiveness. Journal of Accounting Reserch. 20, 589 - 603.

Bunga, W., \& Maria, M. (2017). Group Cohesivenees Sebagai variabel Pemoderasi Pengaruh Partisipasi Anggaran, Budget Empahasis, dan Asimetri Informasi Pada Budgetary Slack. E- Jurnal Akuntasi Universitas Udayana, 20(2), 2302-8556. 
Camman, C. (1976). Effects the Use of Control System. Accounting, Organization, and Society, 44, 301-313.

Chenhall, R., Morris, D. (1986). The Impact of Structure, Environment and Interdependece on The Perceived Usefulness of Management Accounting System. The Accounting Review 61(1), 16-35.

Daniel, Ivo. (2015). Pengaruh Penganggaran Partisipatif Terhadap Kelonggaran Anggaran Dengan Asimetri Informasi dan Locus of Control Sebagai Variabel Moderating. JOM FEKOM, 2.

Dunk, A. (1993). The Effect of Budget Emphasis and Information Asymmetry on The Relation Between Budgetary Participation and Slack. The Accounting Review, 68(2), 400-410.

Dwi, Putri. (2015). Pengaruh Partisipasi Anggaran Terhadap Senjangan Anggaran Dengan Locus of Control Sebagai Variabel Moderating. Jom FKOM, 2.

Eisenhardt, Kathleen M. (1989). Agency Theory: An Assesment and Review. Academy of Management Review,14(1), 57-74

Eka, Y. I. G. (2016). Pengaruh Asimetri Informasi, Penekanan Anggaran Dan Kapasitas Individu Terhadap Senjangan Anggaran Dengan Locus of Control Sebagai Variabel Pemoderasi. E- Journal S1 Universitas Pendidikan Ganesha.

Falikhatun. (2003). Pengaruh Budaya Organisasi, Locus of Control Dan Penerapan System Informasi Terhadap Aparat Unit-Unit Pelayanan Publik. Emprika, 16(2), 263-281.

Faslah, R. (2010). Hubungan Keterlibatan Kerja dengan Turnover Intention pada Karyawan PT. Garda Trimitra Utama. Jurnal Econo Sains, 3(2), 146-151.

Handoko, Jesica. (2006). Pengaruh Tanggung Jawab Dan Locus of Contorol Dalam Keputusan Investasi POURING GOOD MONEY AFTER BAD. ISSN: 1411- 0393.

Jensen, M., and Meckling, W. (1976). Theory of the firm: Managerial Behaviour, Agency Costs, and Ownership Structure. Journal of Financial Economics, 3, 305-360.

Kanungo, R. N. (1982). Measurement of Job and Work Involvement. Journal of Applied Psychology, $341-349$.

Karsam. (2013). The Influence of Participation in Budgeting on Budgetary Slack with Information Asymmetry as a Moderating Variable and its Impact on the Managerial Performance. International Journal of Applied Finance and Business Studies, 1(1), 28-38.

Kartika, Andi. (2010). Pengaruh Komitmen Organisasi dan Ketidakpastian Lingkungan dalam Hubungan antara Partisipasi Anggaran dengan Senjangan Anggaran. Jurnal Kajian Akuntansi, 2(1), 39-60.

Kenis, I. (1979). Effect of Goal Characteristics on Managerial Attitutes and Performance. The Accounting Review 54, 702-721.

Khan, Muhammad Riaz; Ziauddin; Jam, Farooq Ahmed; Ramay, M.,I., (2010). The Impacts of Organizational Commitment on Employee Job Performance. European Journal of Social Sciences, 15(3).

Kren, L. (2003). Effects of Uncertainty, Participation, and Control System Monitoring on the Propensity to Create Budget Slack and Actual Budget 
Slack Created. Advances in Management Accounting, 11, 143-167.

Latuheru, Belianus Patria. (2005). Pengaruh Partisipasi Anggaran Terhadap Senjangan Anggaran Dengan Komitmen Organisasi Sebagai Variabel Moderating. Jurnal Akuntansi dan Keuangan. 7(2), 117-130.

Lawler, E., and Hall, D. (1970). Relationship of Job Characteristic to Job Involvement, Satisfaction and Intricsic Motivation. Journal of Applised Psychology,305-312.

Lukka, K. (1988). Budgetary Biasing in Organizations: Theoritical Framework and Empirical Evidence. Accounting, Organization, and Society, 13, 281301.

Margaret A, Peter B. (1999). The Role of Budgets in Organization Facing Strategic Change. Accounting Organization and Society, 24, $189-204$.

Merchant, K. (1985). Budgeting and Prospersity to Create Budgetary Slack. Accounting, Organization, and Society, 10, 201-210.

Nouri, H. (1994). Using Organizational Commitment and Job Involvement to Predict Budgetary Slack: A Research Note. Accounting, Organization and Society, 3, 289-295.

Onsi, M. (1973). Factor Analysis of Behavioral Variabel Attacting Budgetary Slack the Accounting. Review Juli, 534-584.

Otley. (1980). The Contingency Theory of Management Accounting: Acheivement and Prognosis. Accounting, Organizations and Society, 422.

Soobaroyen, T. (2005). Management Control System and Dysfuntional Behavior: An Emprical investigation. Lecturer in Accounting and Finance United Kingdom University of Wales.

Sugiyono. (2013). Metode Penelitian Bisnis. Bandung: Alfabeta.

Sujana, K. (2010). Pengaruh Partisipasi Anggaran, Penekanan Anggaran, Komitmen Organisasi, dan Ketidakpastian Lingkungan Terhadap Budgetary Slack Pada Hotel Berbintang Di Kota Denpasar. Jurnal Akuntansi Fakultas Ekonomi Universitas Udayana.

Threzasyari, Y. (2017). Pengaruh Partisiapasi Anggaran dan Kejelasan Sasaran Anggran Dengan locus of control sebagai Variabel Pemoderasi. JOM Fekom, 4(1).

Triana, M. (2012). Pengaruh Pertisipasi Aanggaran, Budget empahasis, dan Locus of Control Terhadap Slack Anggaran. E- Journal BINAR AKUNTANSI, 1(1), 2303-1522.

Young, S. M. (1985). Participative Budgeting: The Effects of Risk Aversion and Asymmetric Information of Budgetary Slack. Journal of Accounting Research, 23, 829-842. 